\title{
Synthesis and Characterization of ZnO Nanostructures by Polymeric Precursor Route
}

\author{
R.S. RAzAvi ${ }^{a, *}$, M.R. Loghman-Estarki ${ }^{b}$ And M. FARHAdi-KhouzAni ${ }^{b}$ \\ ${ }^{a}$ Department of Materials Engineering, Malek Ashtar University of Technology, Isfahan, Iran \\ ${ }^{b}$ Department of Materials Engineering, Isfahan University of Technology, Isfahan, Iran
}

\begin{abstract}
Zinc oxide nano- and submicrostructures have been synthesized controllably by polymeric precursor method (Pechini). In this approach, zinc acetate $\mathrm{Zn}\left(\mathrm{CH}_{3} \mathrm{COO}^{-}\right)_{2} \cdot 2 \mathrm{H}_{2} \mathrm{O}$, citric acid and ethylene glycol were used as the source of $\mathrm{Zn}^{2+}$, the chelating agent and the connecting agent, respectively. The microstructure of the $\mathrm{ZnO}$ nanoand submicrostructures was characterized by X-ray diffractometry and scanning electron microscopy and the optical property was investigated by the room temperature photoluminescence spectra. The effect of ethylene glycol to citric acid mole ratio on the morphology and structure of the products was discussed.
\end{abstract}

PACS: 78.67.-n

\section{Introduction}

Scientists have paid a growing attention to the fabrication of $\mathrm{ZnO}$ because of wide range of practical applications in optics, sensors, catalysts, solar cells, data storage, drug delivery and so on [1]. Vapor phase methods involve special equipment complex process control or high temperatures, they are unfavorable for an industrialized process. The chemical methods appear to be of particular interest since they offer the potential of facile scale up, and have flexible processing chemistry. Among chemical methods, sol-gel is an attractive one for preparing nanoparticles because of its easy control, low cost and low fabricating temperature. Pechini's method is one of the sol-gel methods. In this method, some alpha-hydroxycarboxylic, such as citric acid, forms polybasic acid chelates with metal cations and then the chelates polymerize with a polyhydroxy alcohol and forms polyesters. After calcining the gel, nanometer size powders are achieved [2]. To the best of our knowledge, this is the first report on the synthesis of $\mathrm{ZnO}$ nanoand submicrostructures with varying ethylene glycol concentration via Pechini's method.

\section{Experimental}

In a typical experiment, $1 \mathrm{~g} \mathrm{Zn}(\mathrm{AC})_{2} \cdot 2 \mathrm{H}_{2} \mathrm{O}$ and $1 \mathrm{~g}$ citric acid monohydrate $(\mathrm{CA})$ were dissolved in deionized water, and appropriated amounts of ethylene glycol (EG) were then added to form a sol at $50^{\circ} \mathrm{C}$ for $1 \mathrm{~h}$. A white solution was obtained and further heated at $80^{\circ} \mathrm{C}$ for $1 \mathrm{~h}$ to remove excess water. During continued heating at $150^{\circ} \mathrm{C}$ for $1 \mathrm{~h}$, the solution became more and more viscous

\footnotetext{
* corresponding author; e-mail: P8130087@sepahan.iut.ac.ir
}

and finally became a xerogel. To complete drying, xerogel was placed at $250^{\circ} \mathrm{C}$ for $1 \mathrm{~h}$. The result powder is a precursor. In the furnace, we heat-treated the precursor at $600^{\circ} \mathrm{C}$ in air, in a ceramic boat, and then cooled it to reach room temperature.

\section{Results and discussion}

Figure 1 shows the X-ray diffraction (XRD) patterns of the as-synthesized powders prepared at different mole ratios of EG to CA. As can be seen in Fig. 1a, the relatively low signal/noise ratio and some unknown diffraction peaks indicate that the as-synthesized powder prepared through the use of EG:CA mole ratio 2:1 consisted of insufficiently developed crystalline $\mathrm{ZnO}$ and impurities, because the inadequate fuel could not react completely with the zinc nitrate to release enough heat to form the well-developed phase of $\mathrm{ZnO}$. Figure $1 \mathrm{~b}$ shows the XRD pattern of the product at EG:CA mole ratio 4:1. A search-match data base analysis confirmed that this as-synthesized powder has the phase composition of wurtzite $\mathrm{ZnO}$ with $P 63 m c$ structure. The rather stronger (002) peak compared with a standard spectrum in Fig. 1b suggests that the structure of $\mathrm{ZnO}$ has a preferential orientation along (002). This unusual diffraction peak of (002) indicates a preferential orientation along the $c$ axis and a rod-like shape. The rod-like shape was confirmed by transmission electron microscopy (TEM) photographs to be discussed later. When the EG:CA mole ratio increases to $7: 1$, obviously, the crystallinity of the products will improve, as shown in Fig. 1c. Almost all products displayed the XRD peaks corresponding to zincite (JCPDS No. 36-1451).

The effects of the mole ratio EG to CA in the starting solution on the morphology and shape of $\mathrm{ZnO}$ powders are shown in Fig. 2. This figure shows the powder scan- 


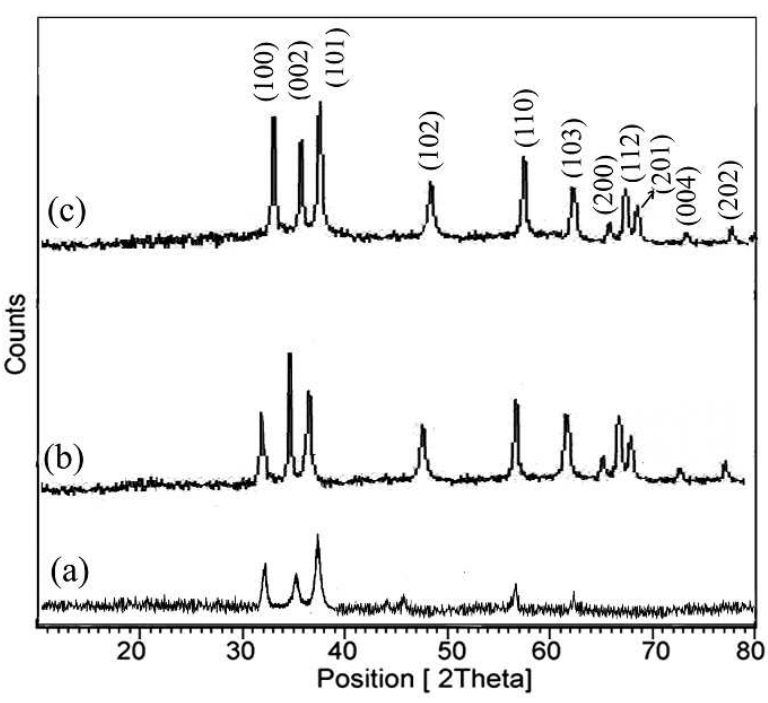

Fig. 1. XRD patterns of $\mathrm{ZnO}$ powders obtained with different EG:CA mole ratio (a) 2:1, (b) 4:1 and (c) 7:1.

ning electron microscopy (SEM) images of the resultant products obtained with EG:CA $(2: 1$ to $7: 1)$. By increasing EG:CA mole ratio from 2:1 to 7:1, morphologies of the as-synthesized $\mathrm{ZnO}$ products can be changed. When EG:CA mole ratio was $2: 1$, nanoparticles with $20 \mathrm{~nm}$ diameter were obtained, while at EG:CA mole ratio 4, rod-like samples (Fig. 2b) with average width $400 \mathrm{~nm}$ and length up to $5 \mu \mathrm{m}$ were obtained. The cross-sections of these rods were circular. Upon increasing the mole ratio EG:CA to 7:1, the amount of the circular cross-section in the products decreases as illustrated in Fig. 2c and rod-like $\mathrm{ZnO}$ with hexagonal cross section was obtained. Their diameter is tapered varying from $\approx 500 \mathrm{~nm}$ in the middle of the nanorods to $300 \mathrm{~nm}$ at the end.

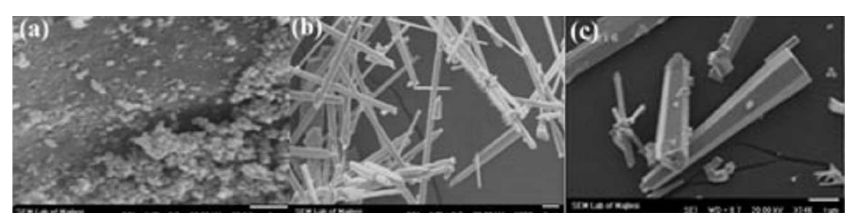

Fig. 2. SEM images of $\mathrm{ZnO}$ powders obtained with different EG:CA mole ratio (a) 2:1, (b) 4:1 and (c) 7:1 (scale bar is $1 \mu \mathrm{m}$ ).

Figure $3 \mathrm{a}$ and b show PL spectra of the as-synthesized products with EG:CA mole ratio 2:1 and 4:1, respectively. Both samples exhibited two peaks: the as-grown sample turns to be broad and dominant in the UV region at $\approx 374 \mathrm{~nm}$ and $380 \mathrm{~nm}$, respectively, and very weak peak at $\approx 510 \mathrm{~nm}$ in the visible region. However, in all cases the near-band edge (NBE) emission is dominating over the deep level emission.

Vanheusden et al. proposed the mechanism of green emission in photoluminescence spectra and reported that the green emission is due to the recombination of the elec- trons in singly occupied oxygen vacancies in $\mathrm{ZnO}$ while the emission results are due to the recombination of a photogenerated hole with an electron occupying the oxygen vacancies [3]. However, the green yellow emission in our sample can be negligible compared with the very intensive sharp UV emission.

Therefore, the results of PL spectrum show that our method can produce a low concentration of oxygen vacancies and high optical quality of $\mathrm{ZnO}$ nano- and submicrostructures. Furthermore, the intensity of hexagonal $\mathrm{ZnO}$ submicrorods is much lower than those of other morphologies in PL curves, as shown in Fig. 3c. As we know, oxygen vacancies are believed to be the main defects causing the green $\mathrm{PL}$ in $\mathrm{ZnO}$ [3]. It has also been reported by Vanheusden et al. [4] that free carrier depletion at the particle surface, and its effect on the ionization state of the oxygen vacancy, can strongly impact the green emission intensity. From this point, it might be deduced that different morphologies, when exposed to air, may lead to different surfaces of depletion of the above three powders, which has also been confirmed by Feng et al. [5]. So the surface of depletion in the hexagonal $\mathrm{ZnO}$ submicrorods may be less than other morphologies. This might be attributed to the decreasing trend at $510 \mathrm{~nm}$ in Fig. 3c. It should be stated that a better understanding of the $\mathrm{ZnO}$ PL shown in Fig. 3 demands more experimental and theoretical work.

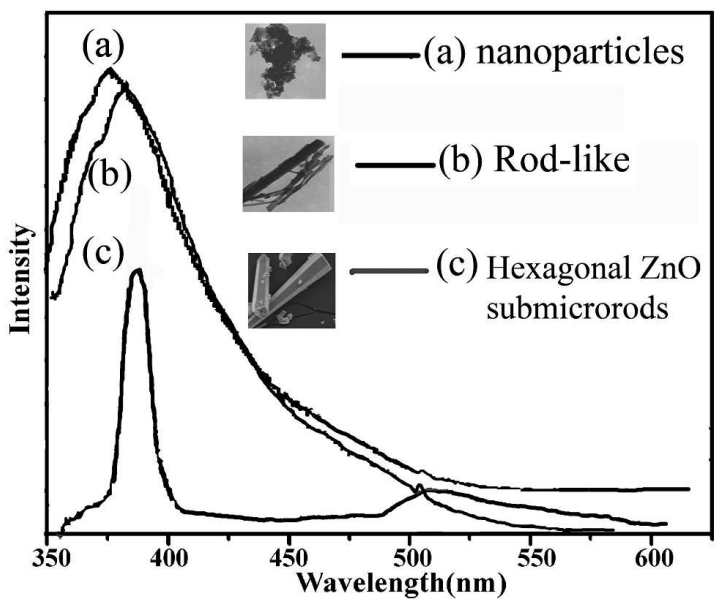

Fig. 3. PL spectra of $\mathrm{ZnO}$ : (a) nanoparticles, (b) rod-like and (c) hexagonal submicrorods.

Pechini's method is based on polymerization of metal citrates using ethylene glycol (polyester chelates metal ions) [2]. As we know, the formation of polyesters is a chemical equilibrium. In chemistry, Le Châtelier's principle, also called the Chatelier principle, can be used to predict the effect of a change in conditions on a chemical equilibrium. Using Le Chatelier's principle we can predict that the amount of polyesters will increase, decreasing the total change in ethylene glycol. Because of this, the crystallinity of the products is improved with increasing of EG:CA mole ratio. If we are to add a species 
to the overall reaction, the reaction will favor the side opposing the addition of the species. Likewise, the subtraction of a species would cause the reaction to fill the "gap" and favor the side where the species was reduced. This observation is supported by the collision theory. As the concentration of ethylene glycol is increased, the frequency of successful collisions of that reactant would increase also, allowing for an increase in forward reaction, and generation of the product. Even if a desired product is not thermodynamically favored, the end product can be obtained if it is continuously removed from the solution [6].

\section{Conclusions}

The $\mathrm{ZnO}$ nano- and submicrostructures such as rod-like, spherical and hexagonal submicrorods have been fabricated by a simple Pechini approach. Rod-like and spherical $\mathrm{ZnO}$ samples show strong near-band edge (NBE) emission generated by the free exciton recombination and very weak deep level emission (DPE) caused by the impurities and structural defects such as oxygen vacancies and interstitials of zinc. A very strong
UV emission at $\approx 384 \mathrm{~nm}$ and weak green emission at $\approx 510 \mathrm{~nm}$ are observed in the PL spectra of one kind of $\mathrm{ZnO}$ nanocrystals, i.e. hexagonal $\mathrm{ZnO}$ submicrorods, which might indicate the presence of a greater fraction of oxygen vacancies in this sample. It is anticipated that method presented in this work, offers a solution to controlling the morphology of metal oxide crystals.

\section{References}

[1] Z.L. Wang, Matt. Today 7, 26 (2004).

[2] S. Sakka, H. Kozuka, Handbook of Sol-Gel Science and Technology Processing, Characterization and Applications, 2nd ed., Kluwer Academic, 2008, p. 60.

[3] K. Vanheusden, C.H. Warren, W.L. Tallant, D.R. Voigt, J. Appl. Phys. 79, 7983 (1996).

[4] K. Vanheusden, C.H. Warren, W.L. Tallant, D.R. Voigt, Appl. Phys. Lett. 68, 403 (1996).

[5] P. Feng, Q. Wan, T.H. Wang, T.H., Appl. Phys. Lett. 87, 213111 (2005).

[6] P.W. Atkins, Elements of Physical Chemistry, 3rd ed., Oxford University Press, 1993, p. 114. 